\title{
Palladium(II)-Catalyzed Enyne Coupling Reaction Initiated by Acetoxypalladation of Alkynes and Quenched by Protonolysis of Carbon-Palladium Bond
}

\author{
Ligang Zhao, Xiyan Lu* and Wei Xu
}

State Key Laboratory of Organometallic Chemistry, Shanghai Institute of Organic Chemistry, Chinese Academy of Sciences, 354 Fenglin Lu, Shanghai, 200032, China

\section{Supporting Information (II)}

Copies of ${ }^{1} \mathrm{H}$ NMR and ${ }^{13} \mathrm{C}$ NMR spectra:

Compound 12b-g

S2-S14

Compound 14a-b

S15-S18

Compound 16a

S19-S20

Compound 18

S21-S22

Compound 20

S23-S25

Compound 22

S26-S27

Compound 24

S28-S29

Compound 26

S30-S31 


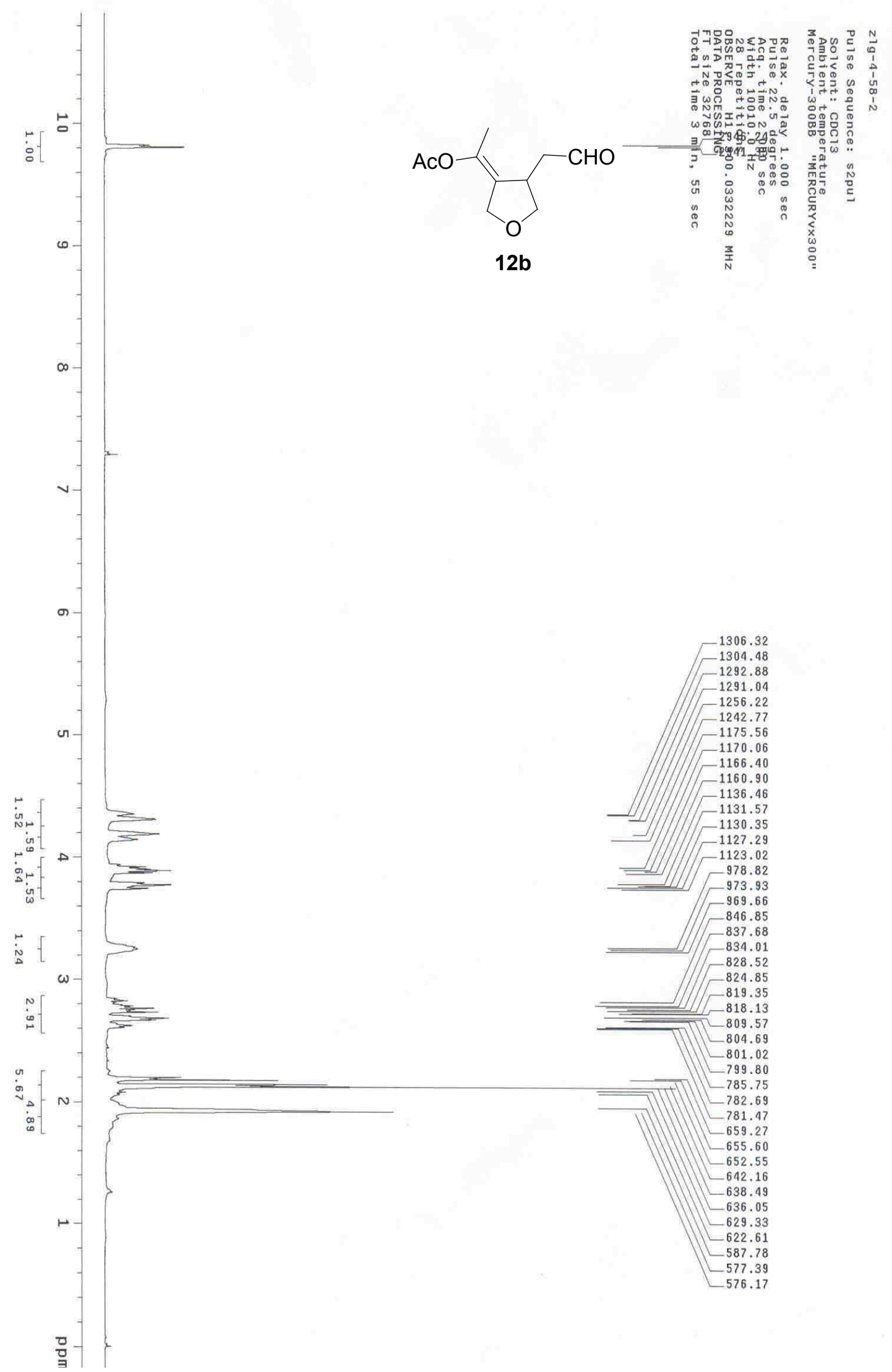



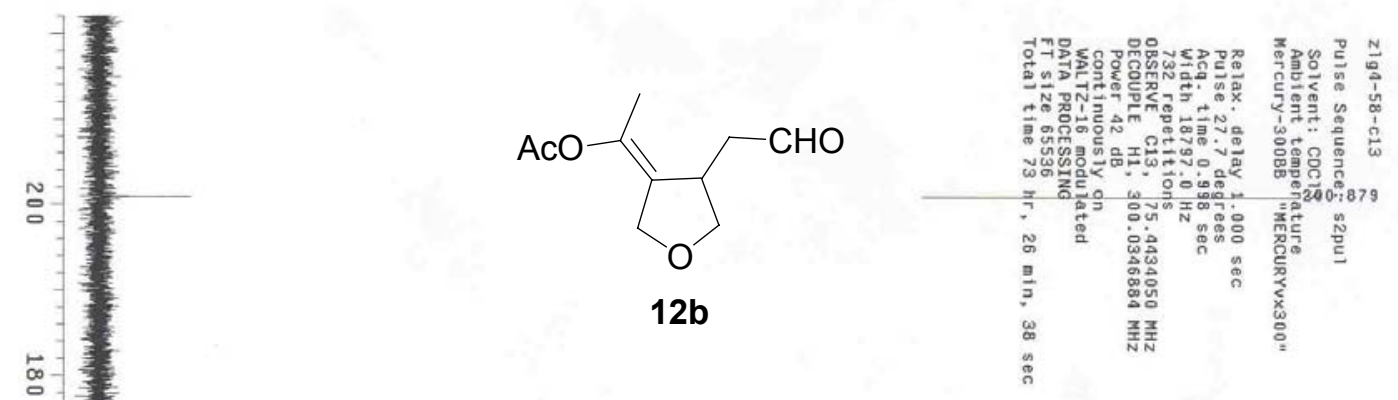

品

$-168.692$

홍

占

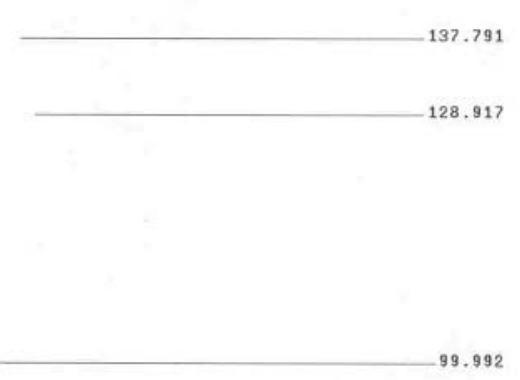

:

ํ.

99.992

$\infty$

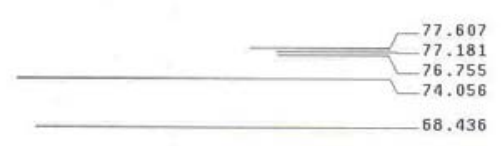

I

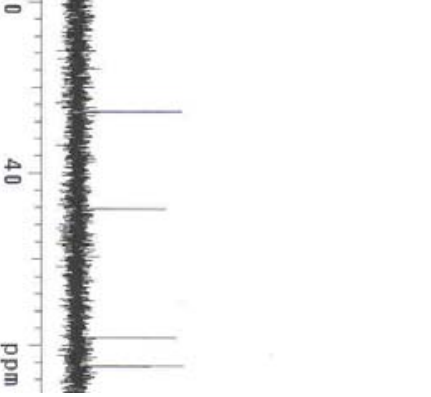

47.108

35.786 


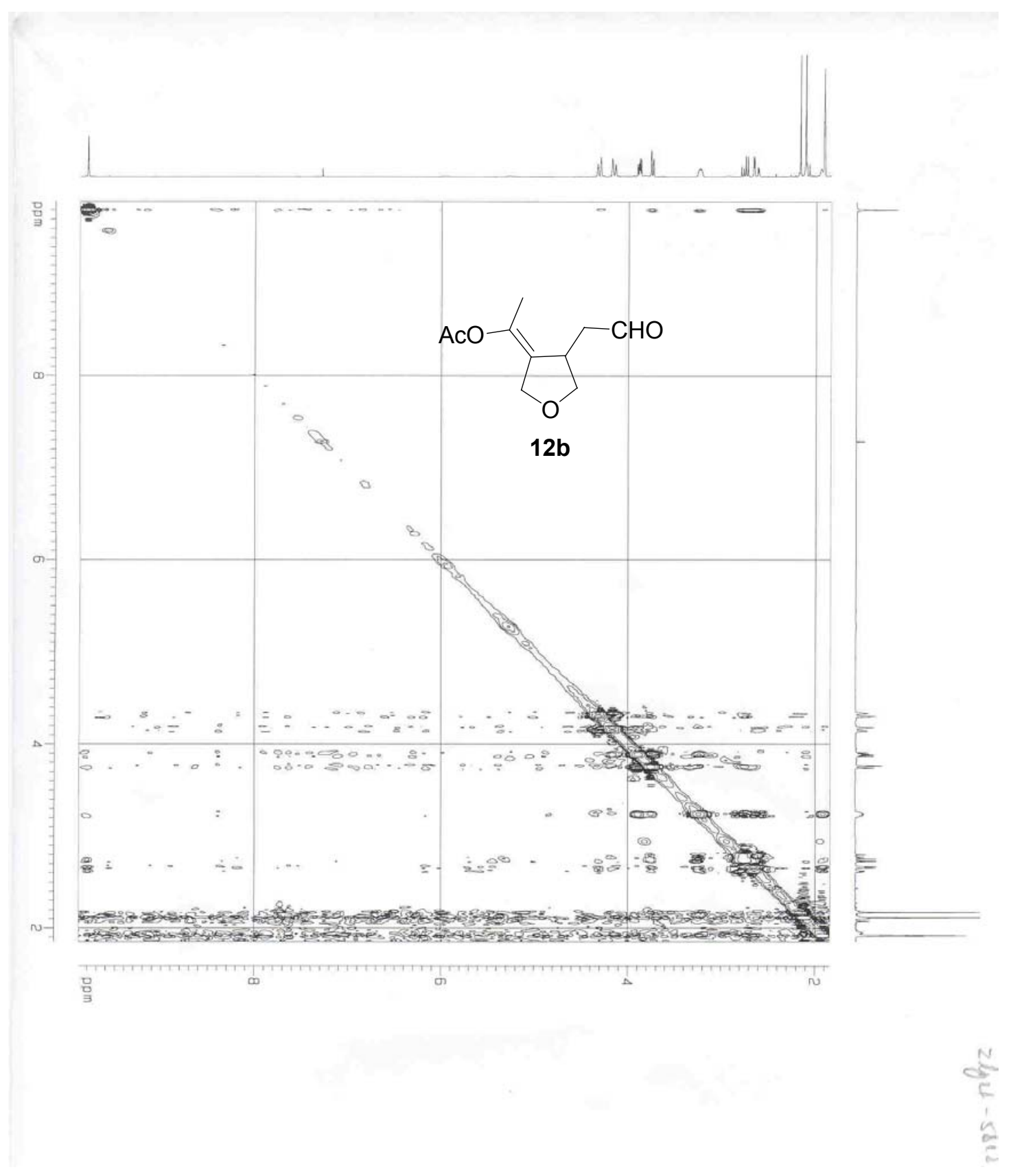




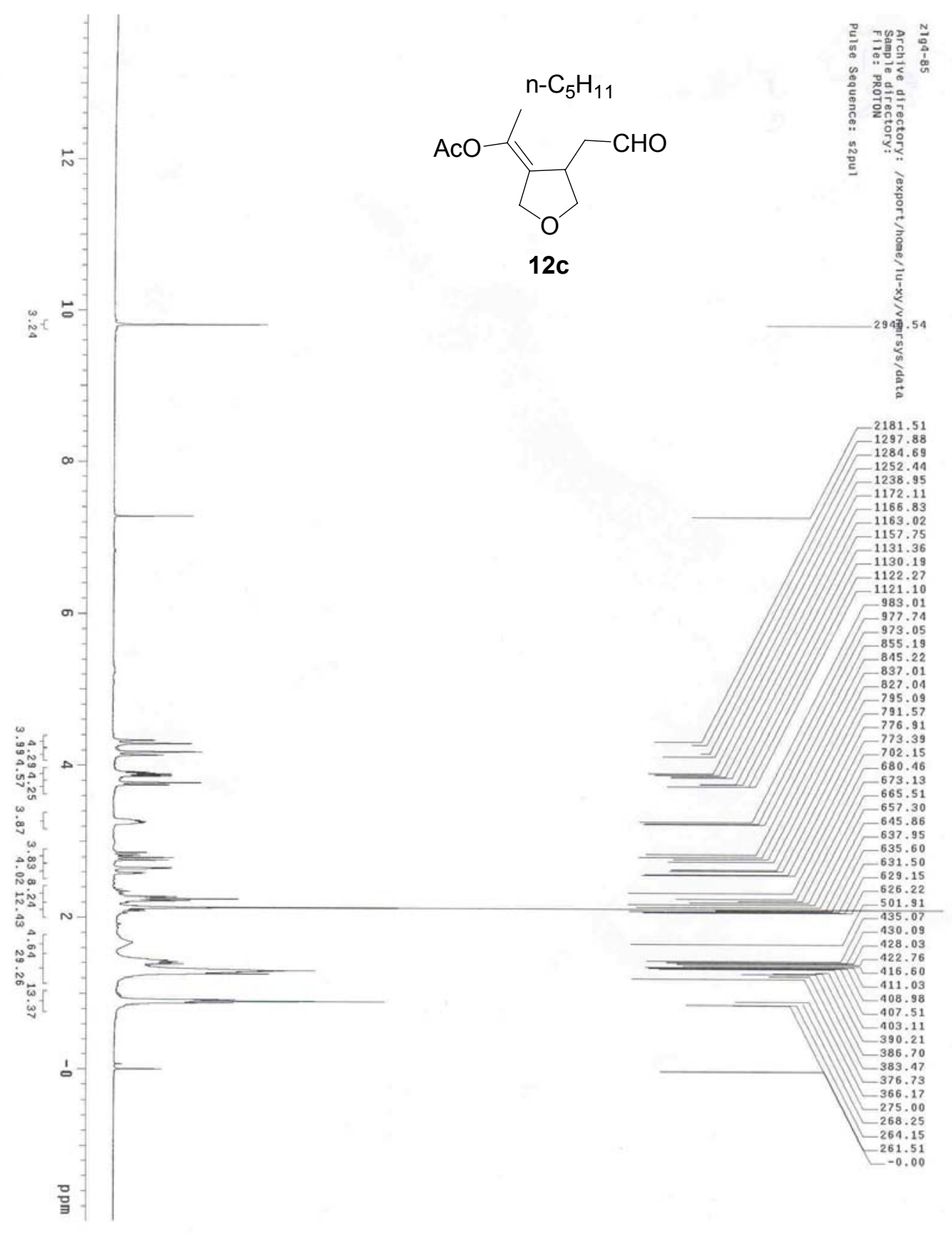




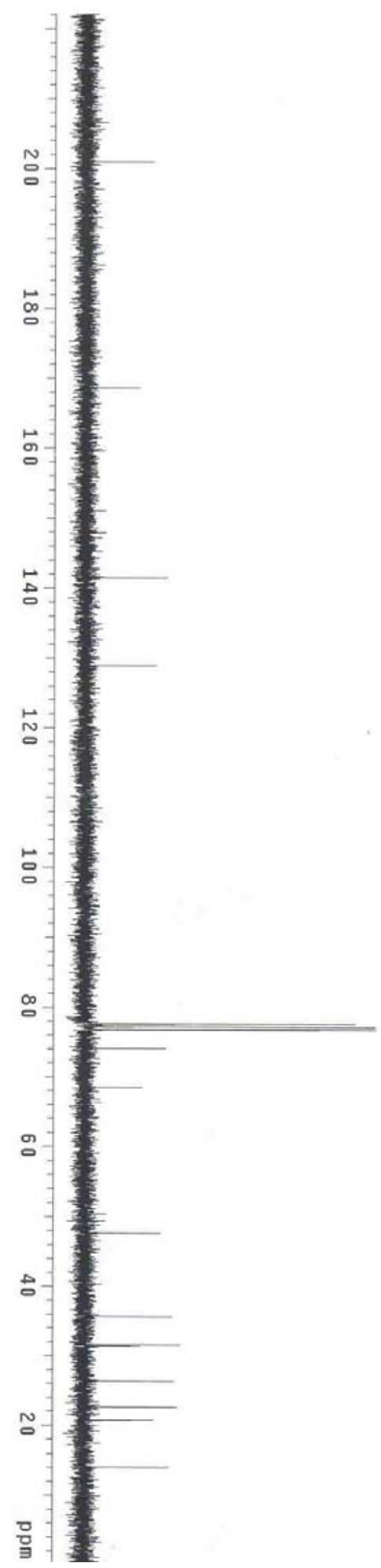

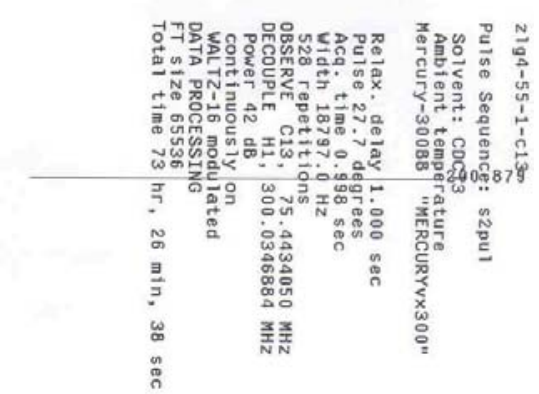

168.533

$-141.395$ $-128.917$

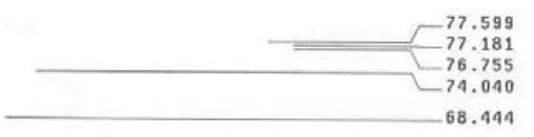

47,632

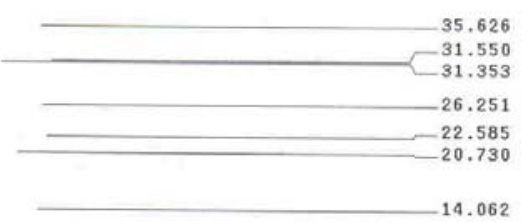




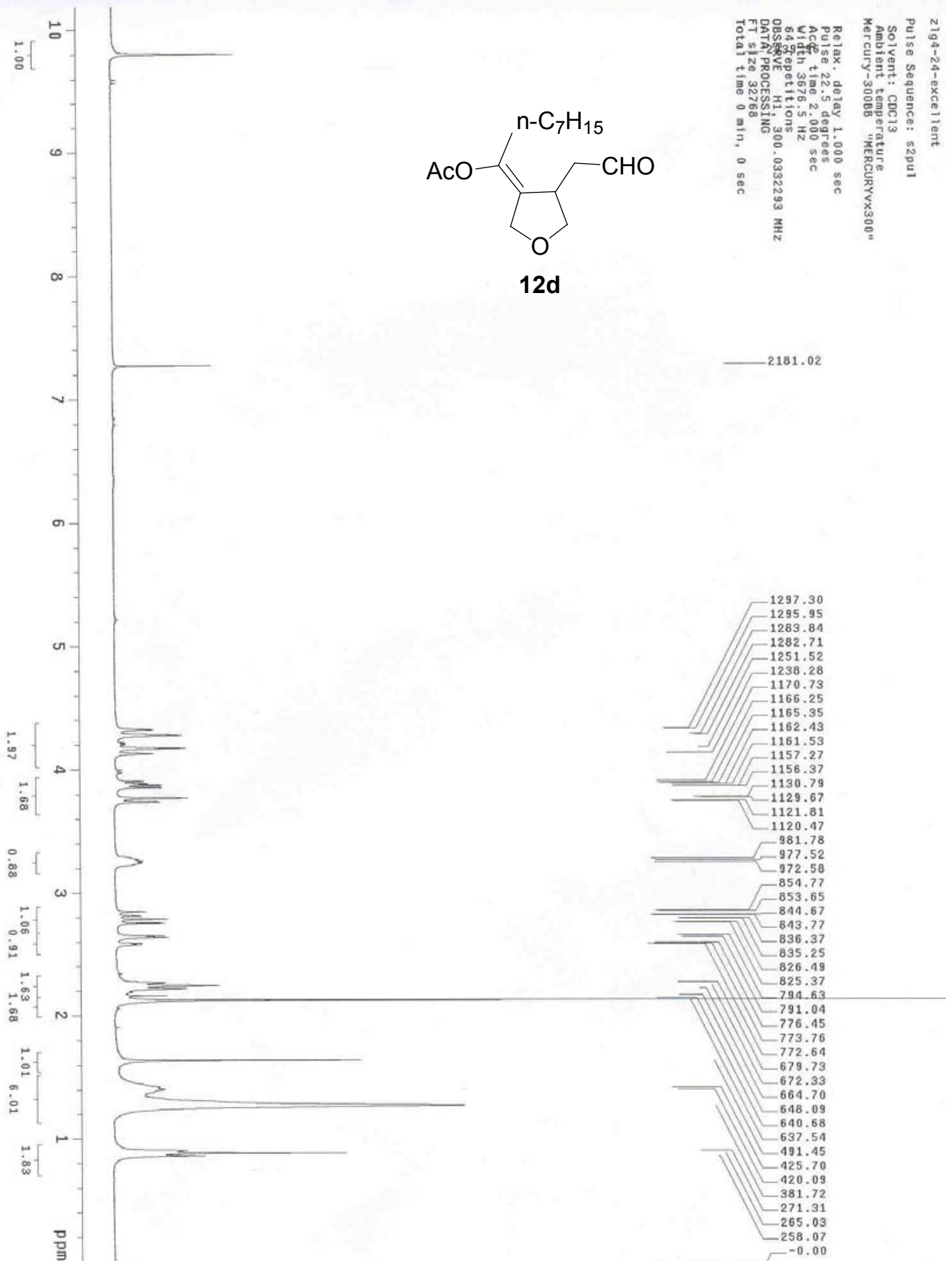



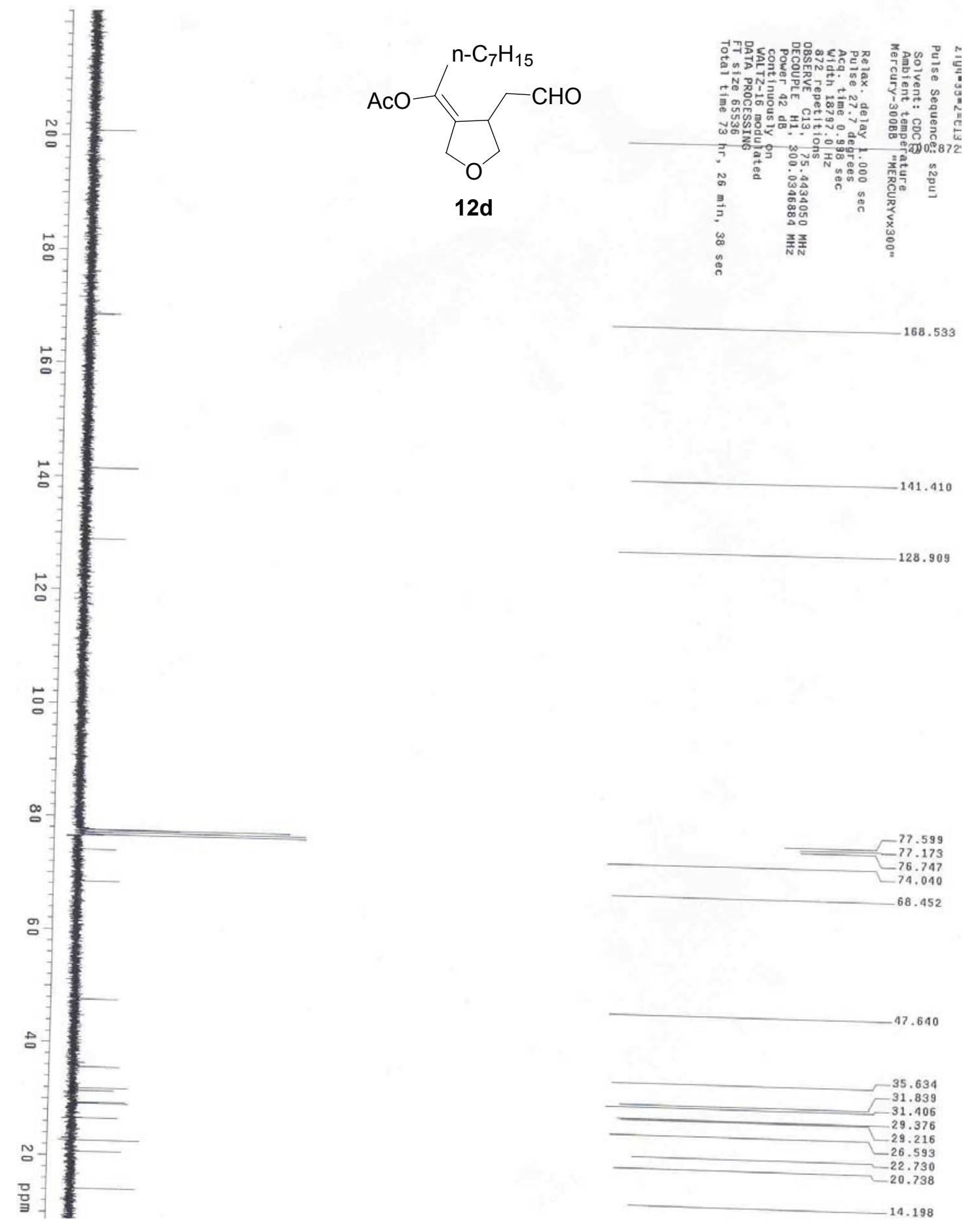

$-168.533$

$-141.410$

$-128.909$

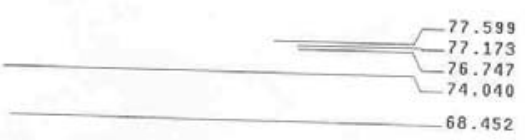

47.640

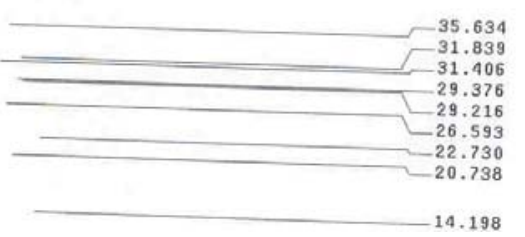




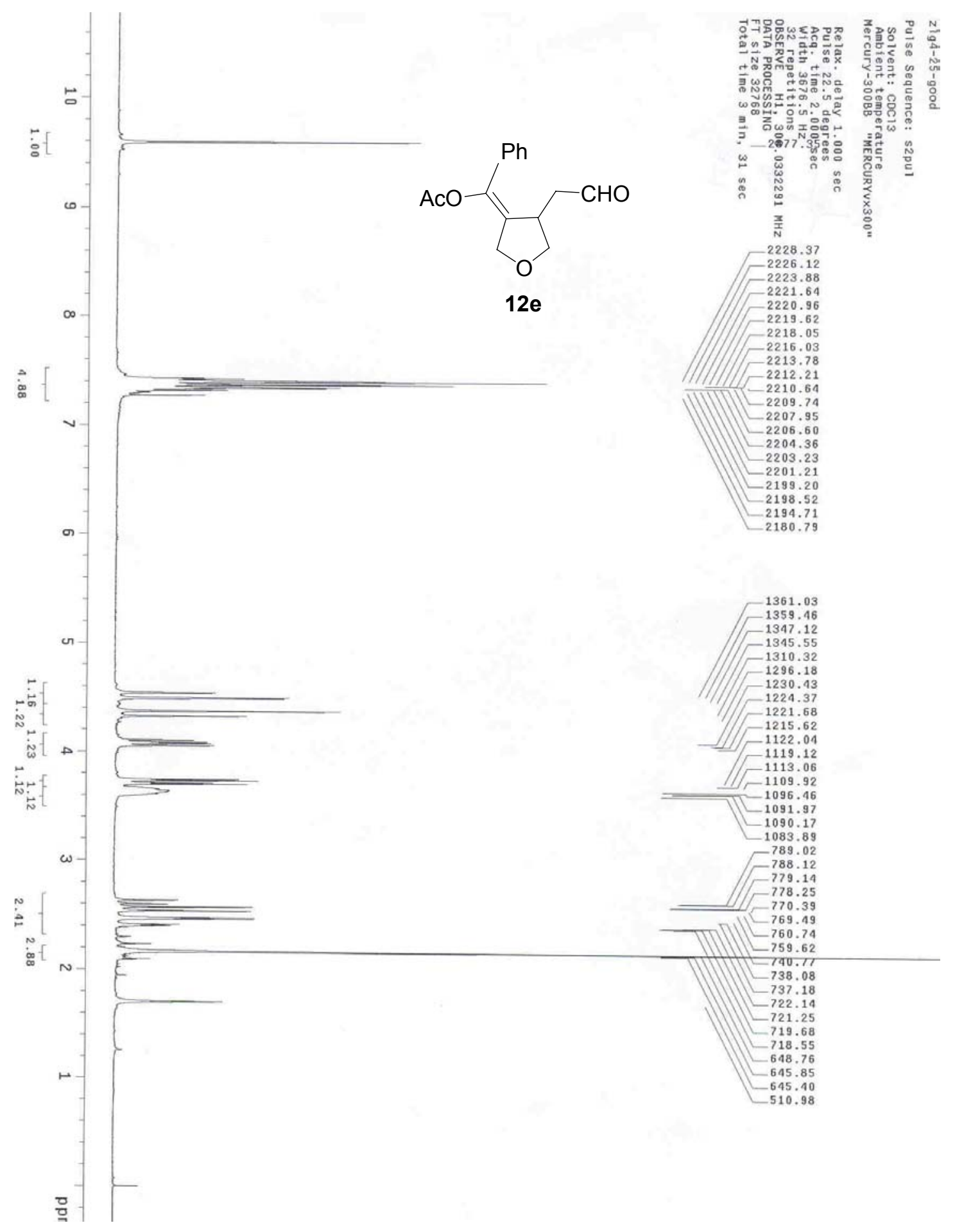




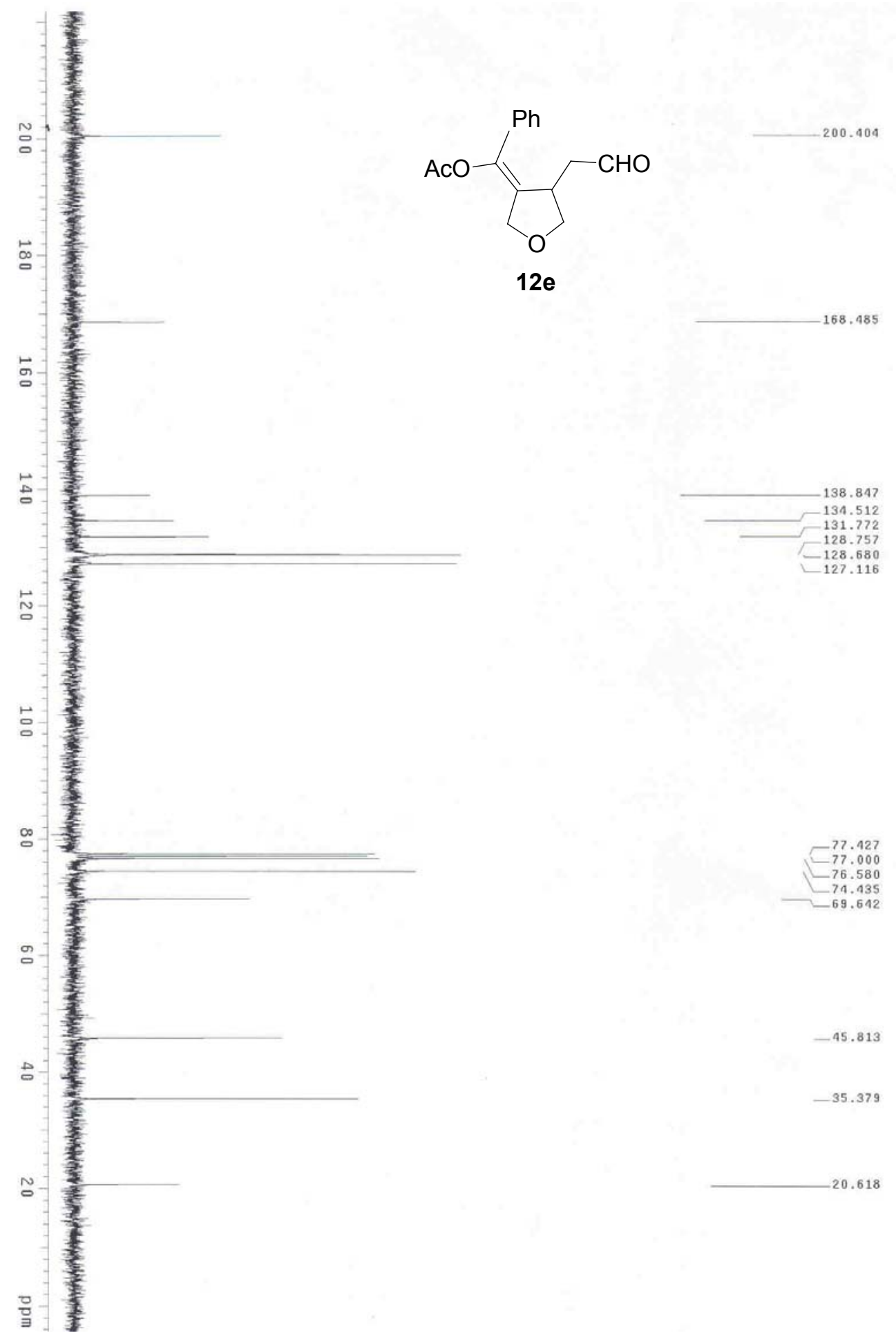



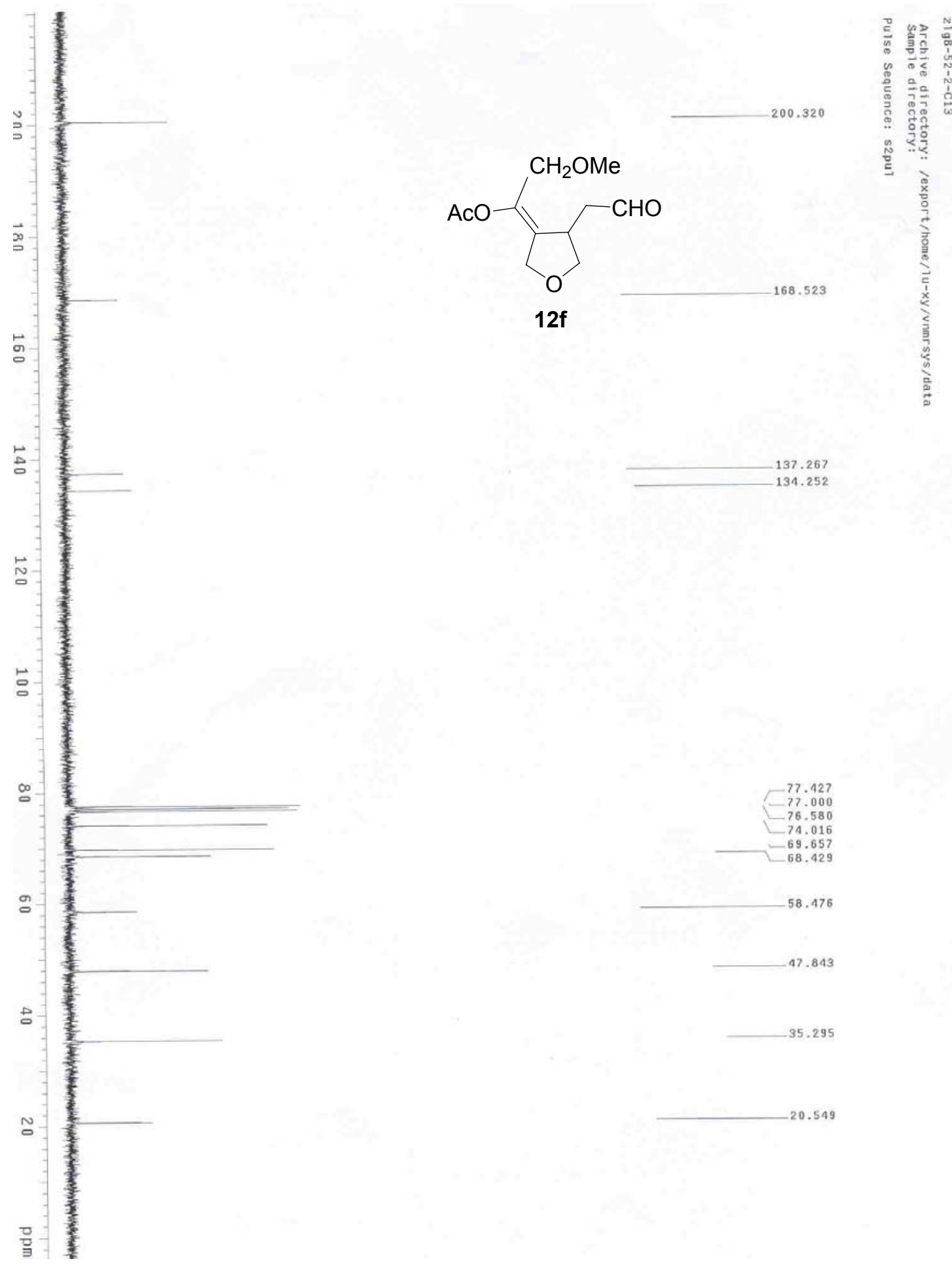

$-35.295$

$-20.549$ 


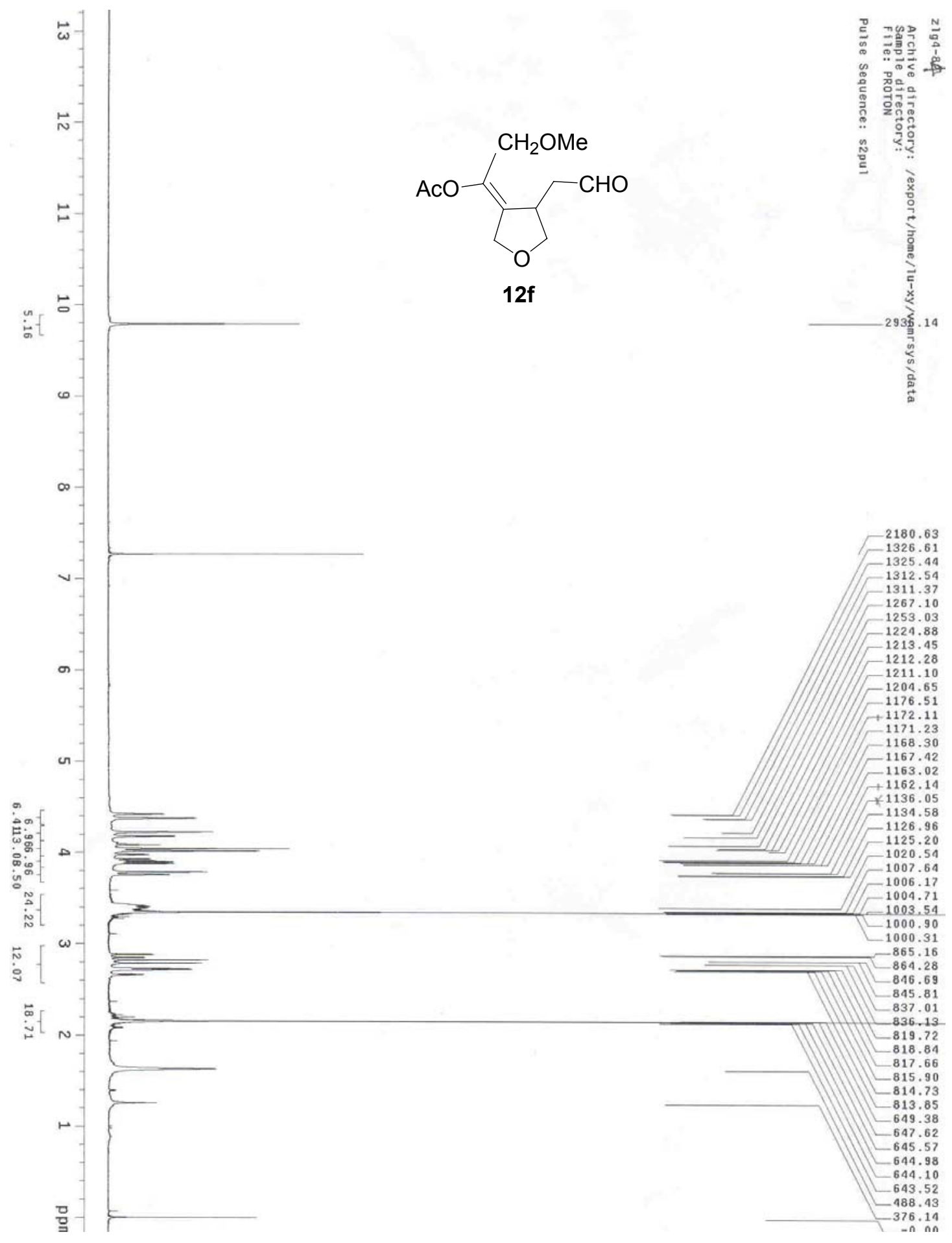




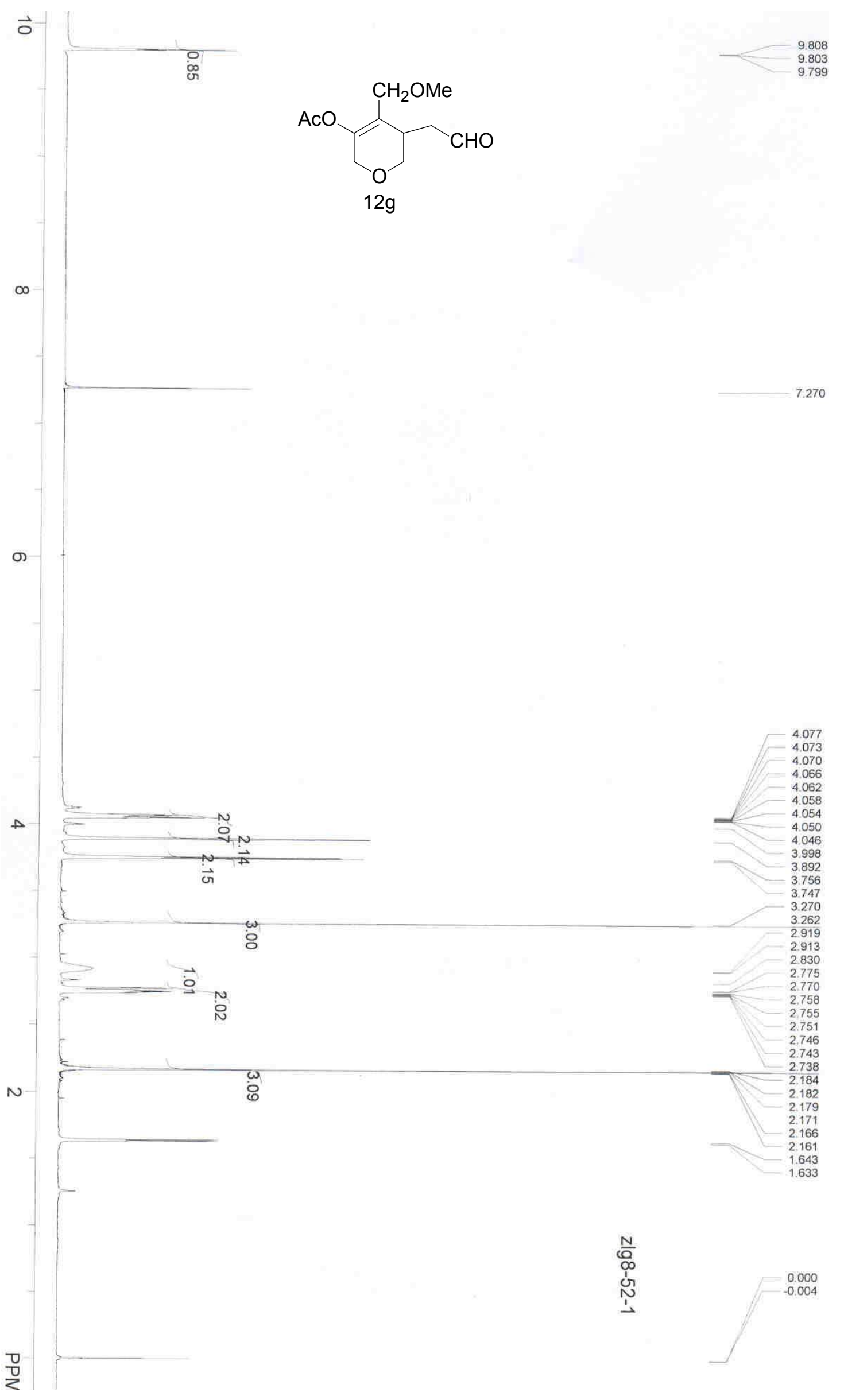



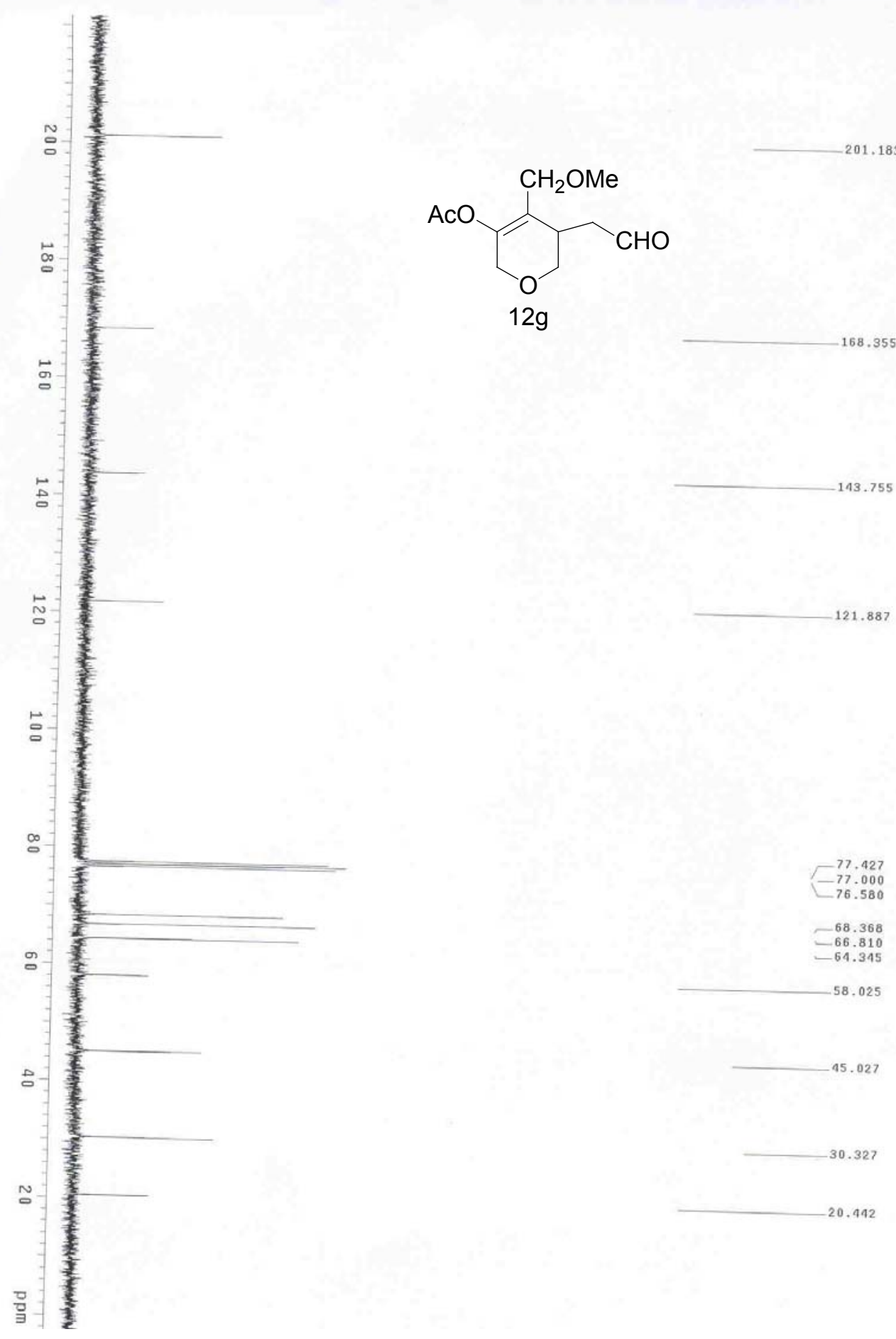


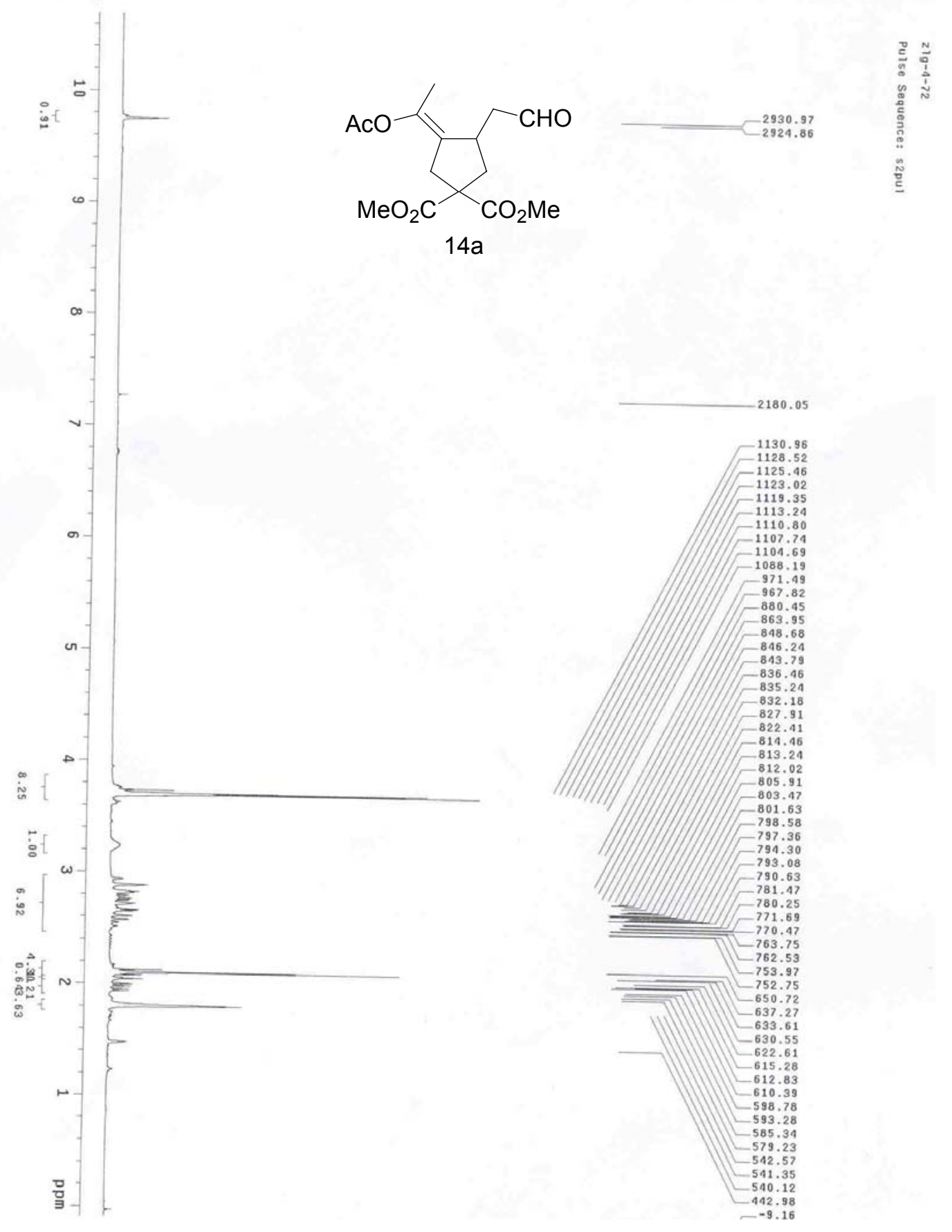



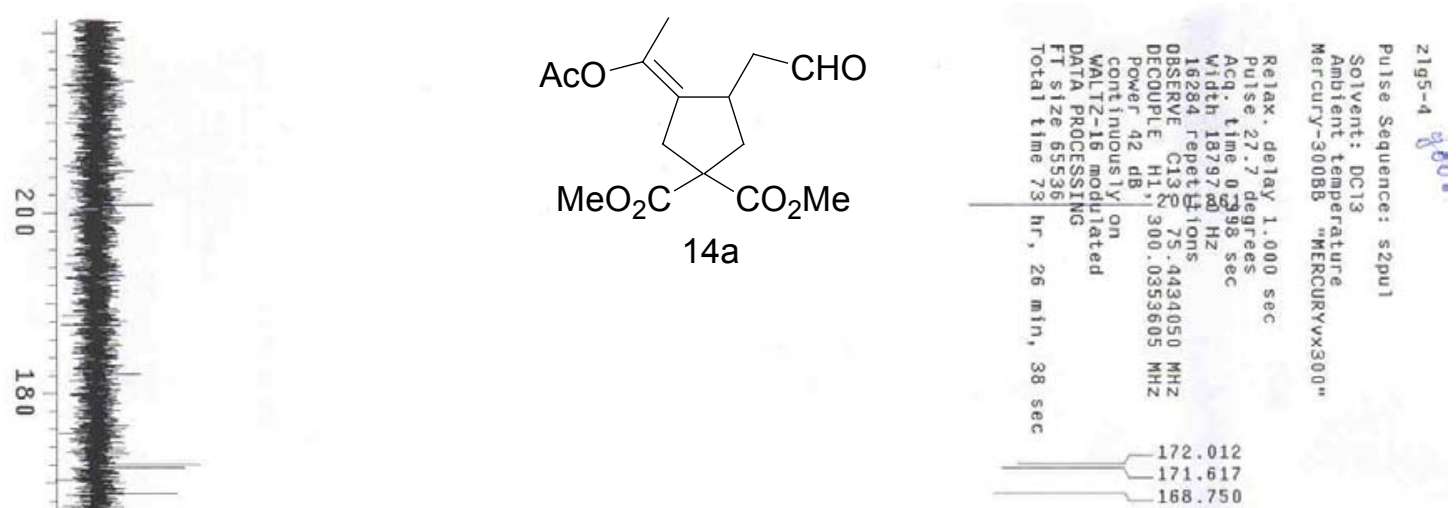

음

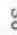

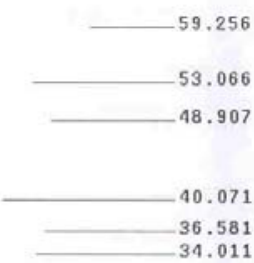

$-20.925$

$-17.085$

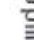




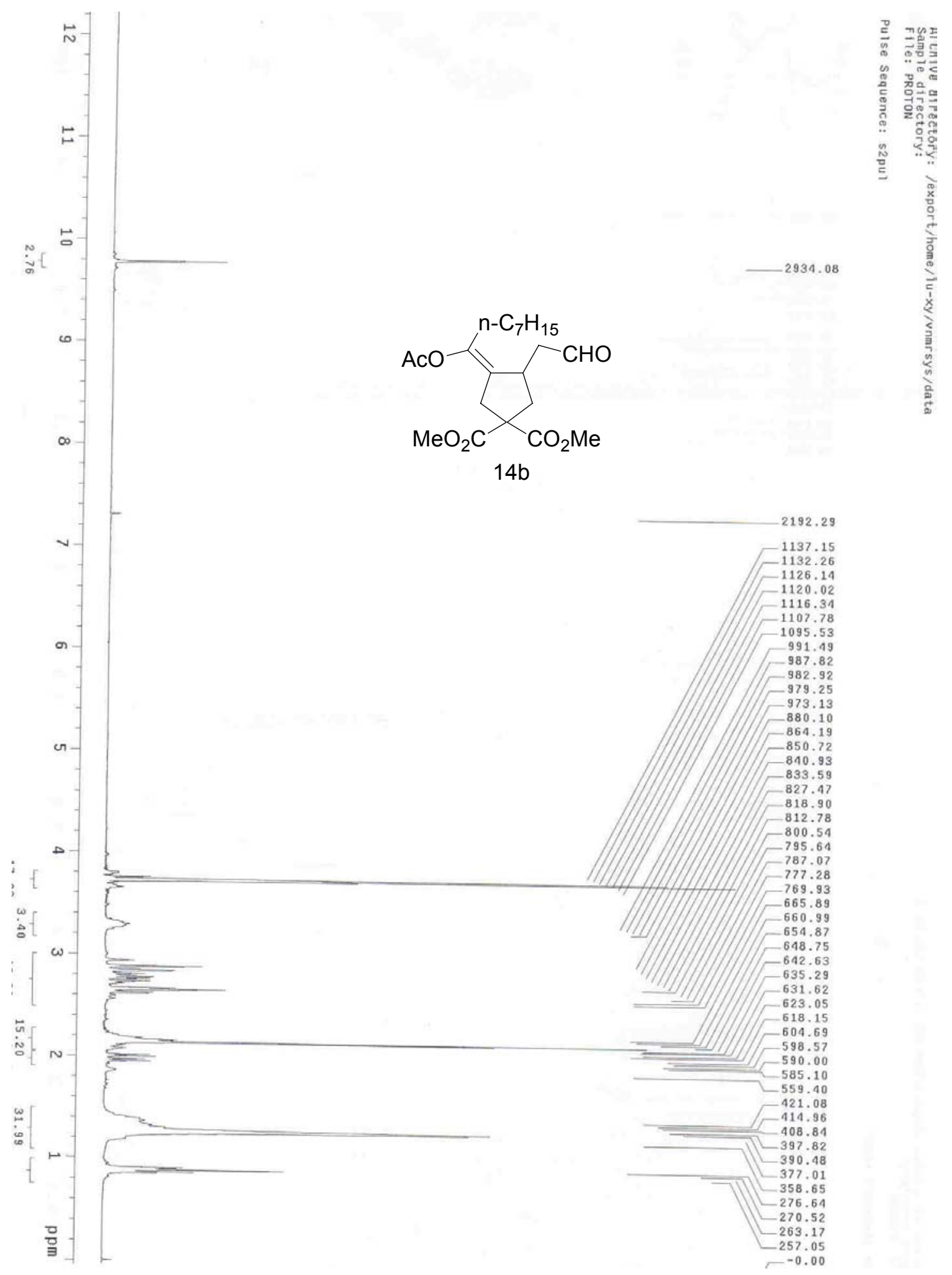



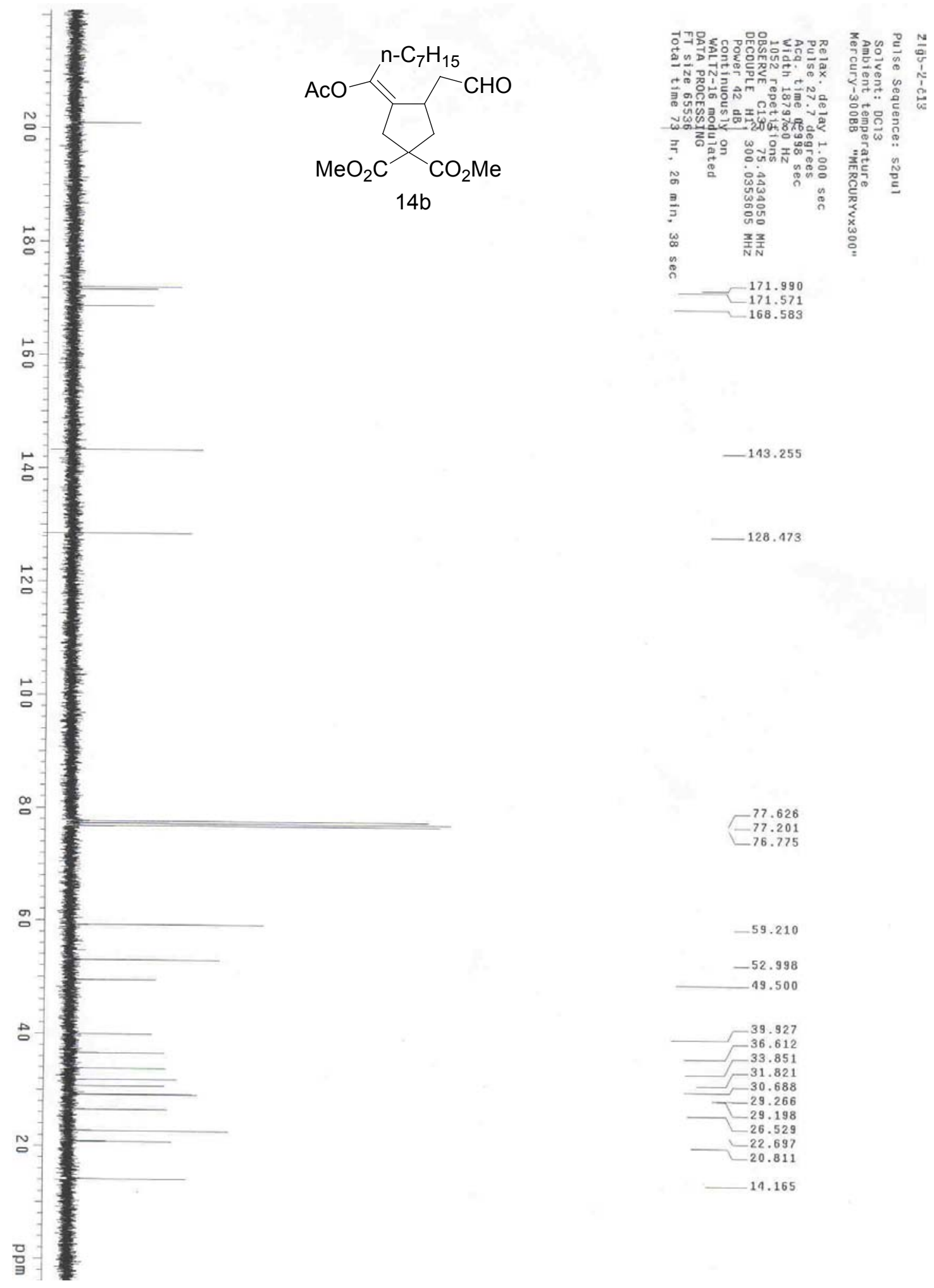

$-143.255$

$-128.473$

$-77.626$

$-76.775$

$-59.210$

$-52.998$

$-49.500$

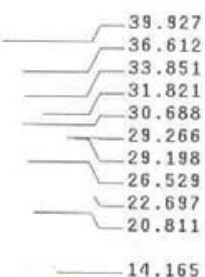




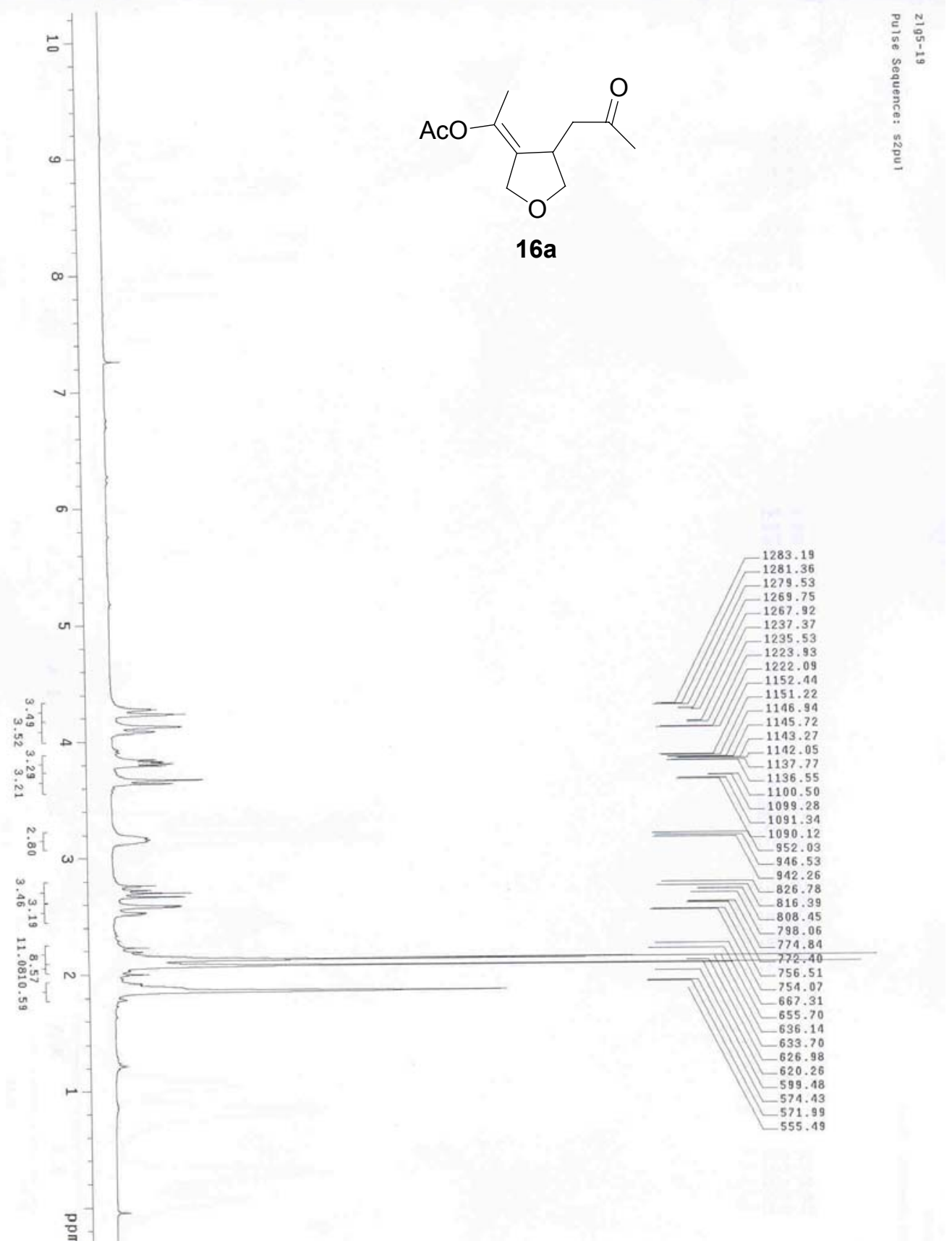



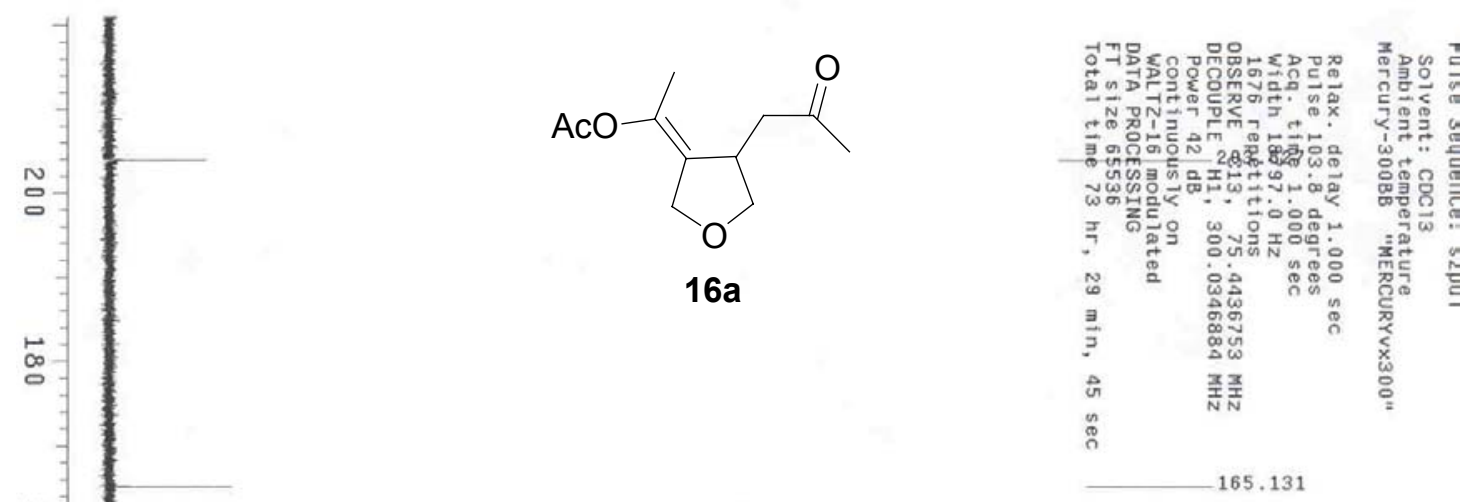

官

s

$\stackrel{\infty}{\circ}$

응.

部

133.796

125.705
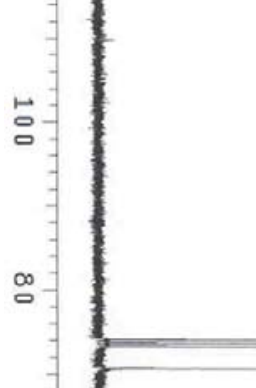

o

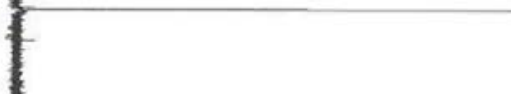

$\stackrel{8}{\circ}$

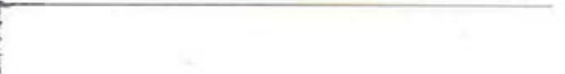

$-42.771$

$-33.221$

$-26.857$

N

$-17.223$

$-13.770$

믑 


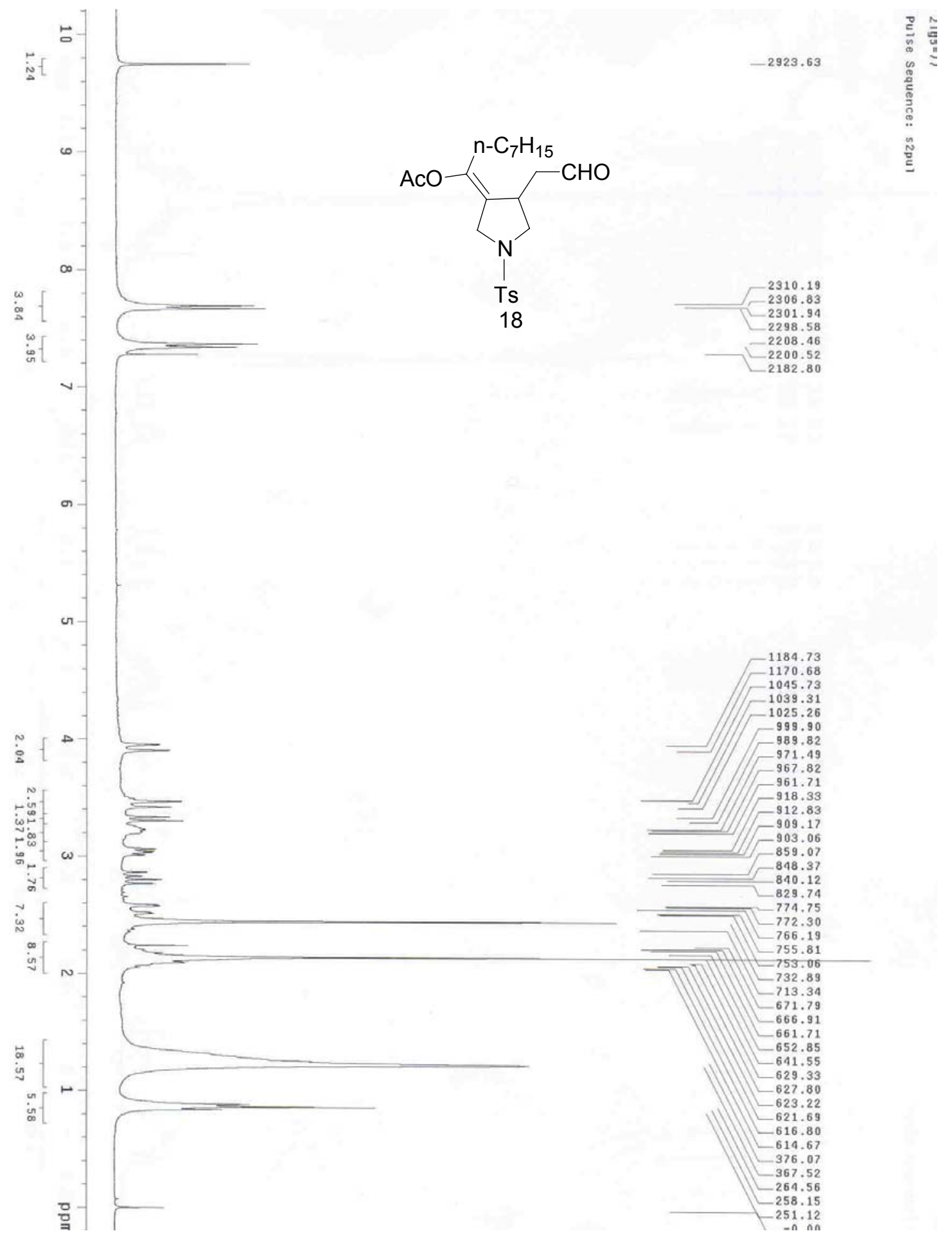



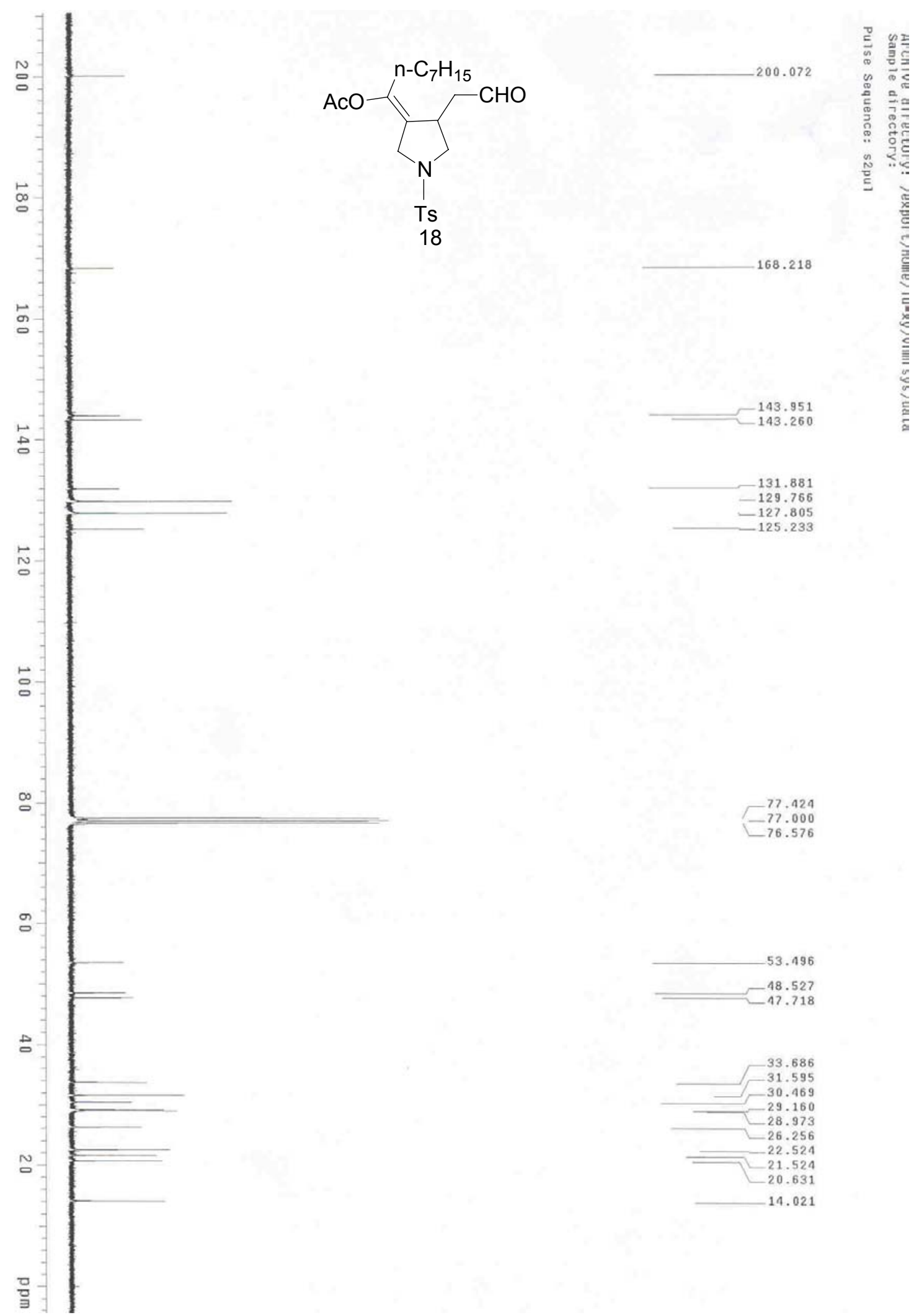


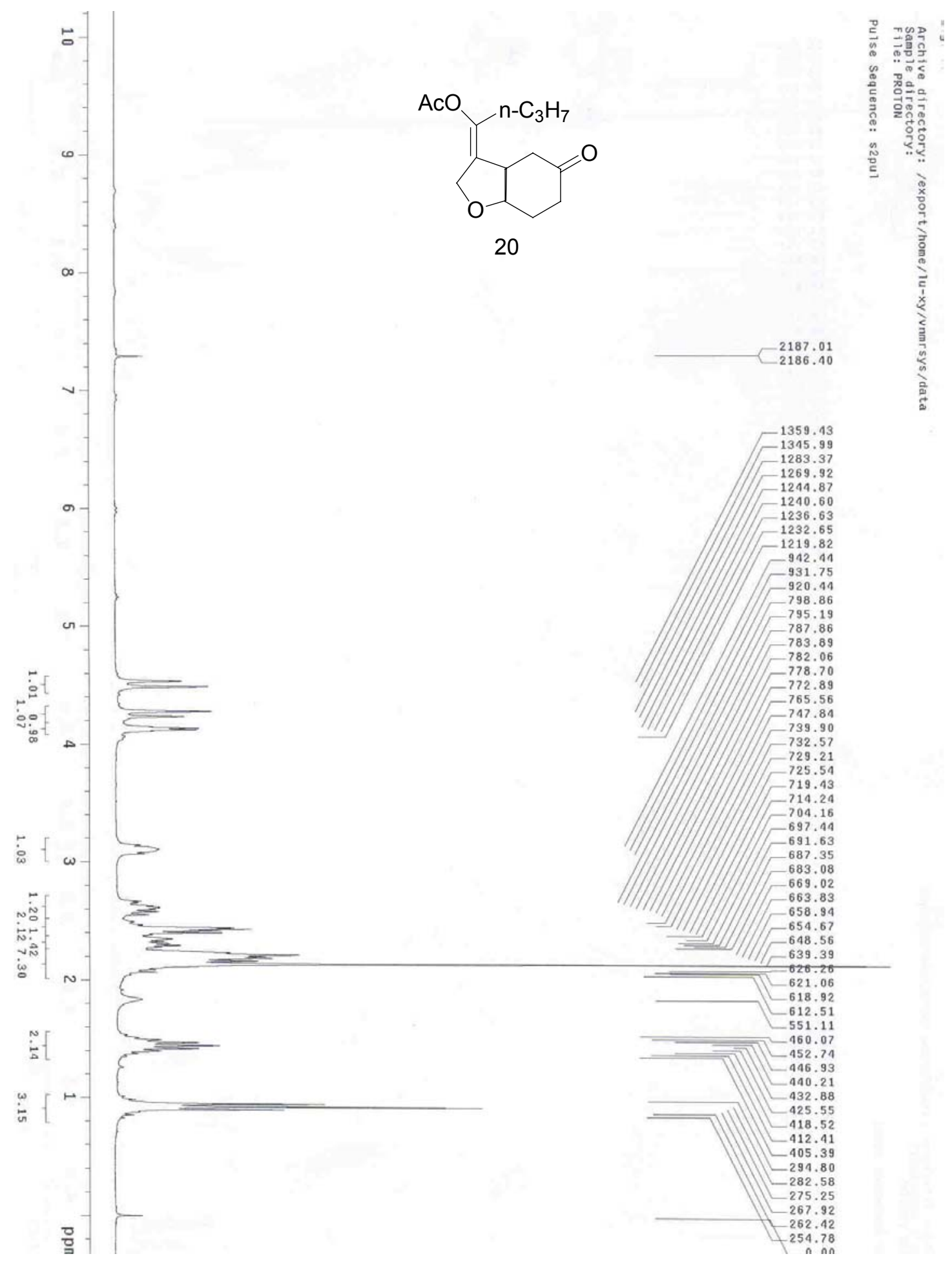



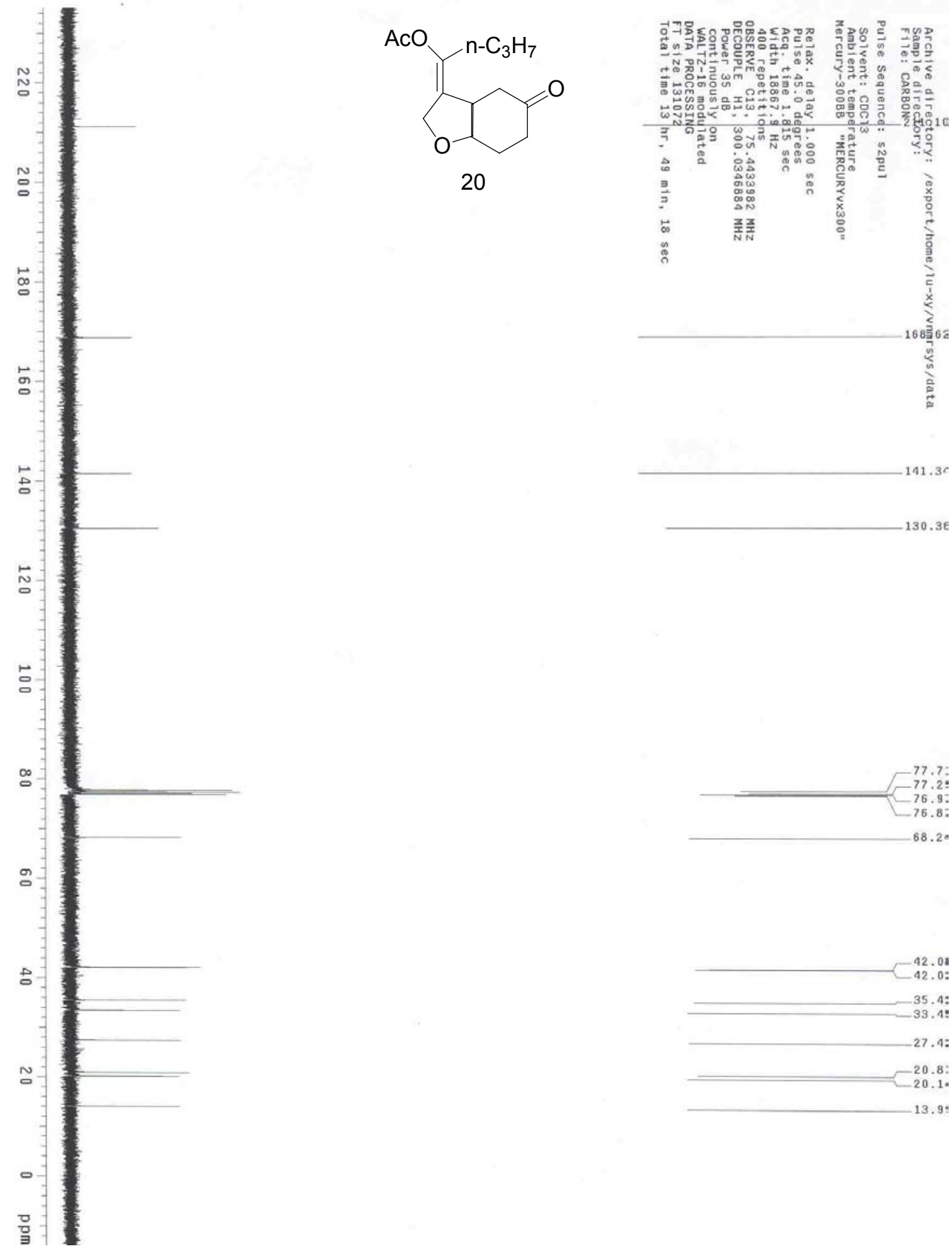

-77.2 :

$-76.9:$
$-76.8:$

-68.2 "

42.01
-42.0

-35.4 :

$-33.49$

20.8

-20.1 .

$13.9=$ 







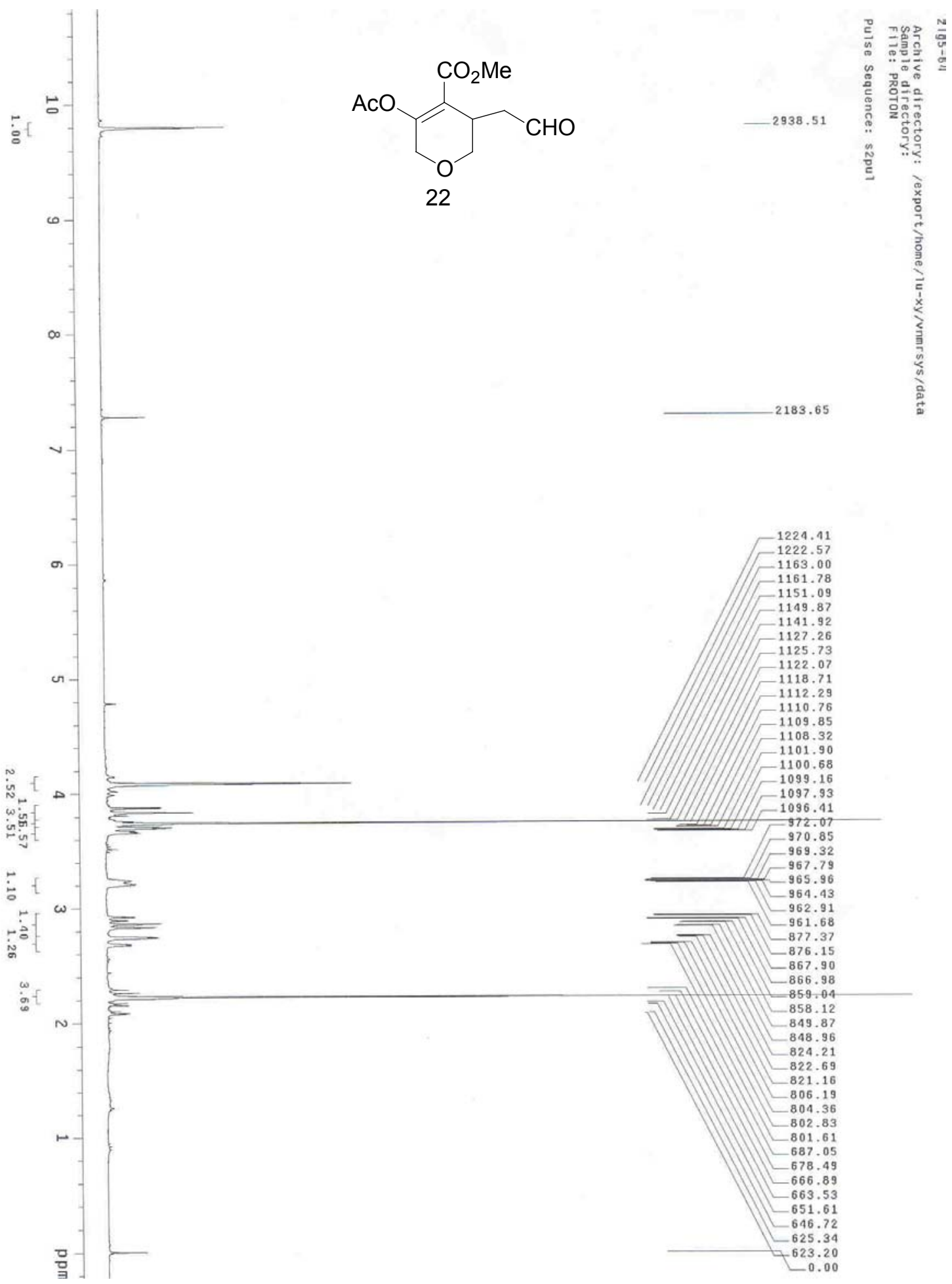



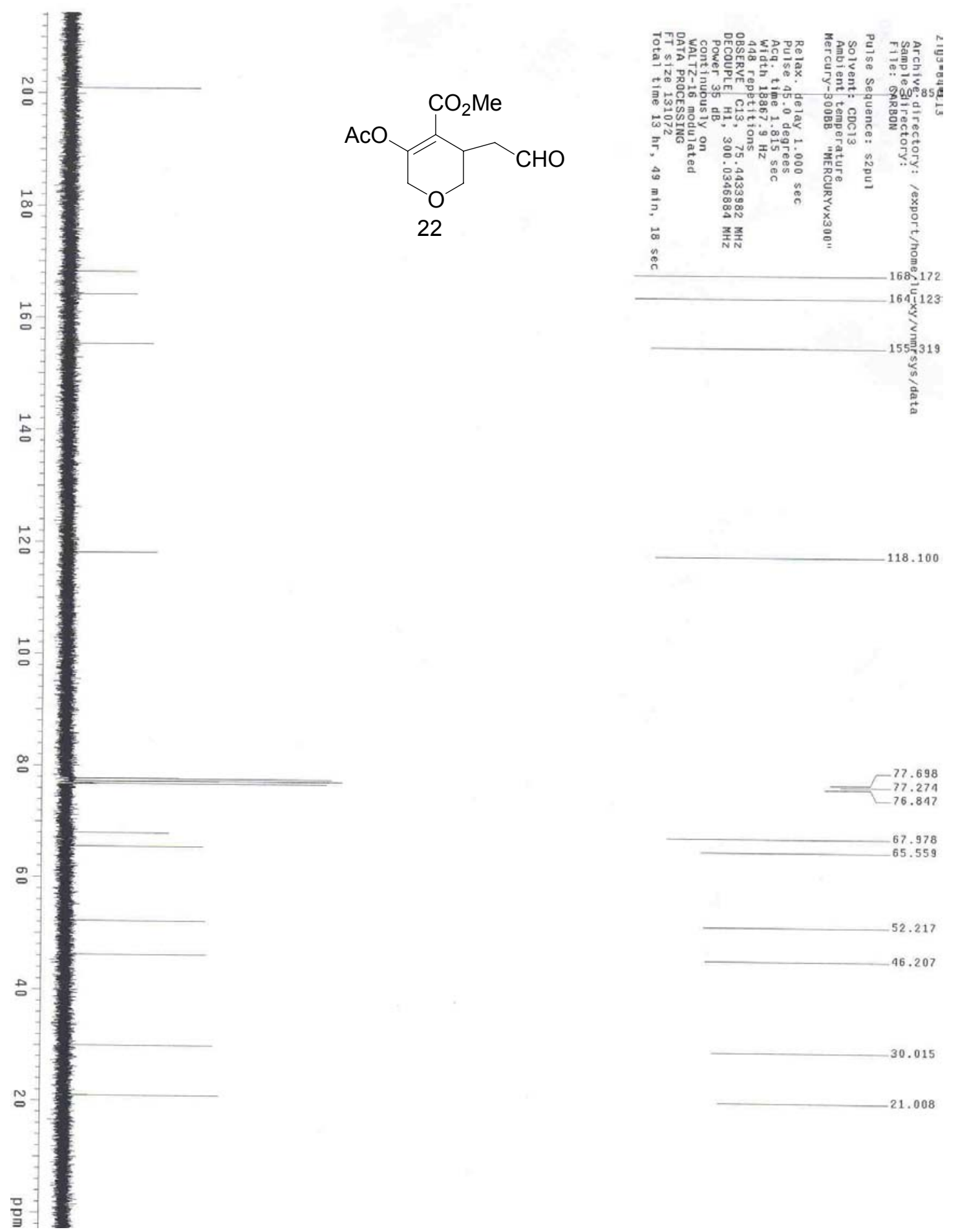

$-118.100$ 


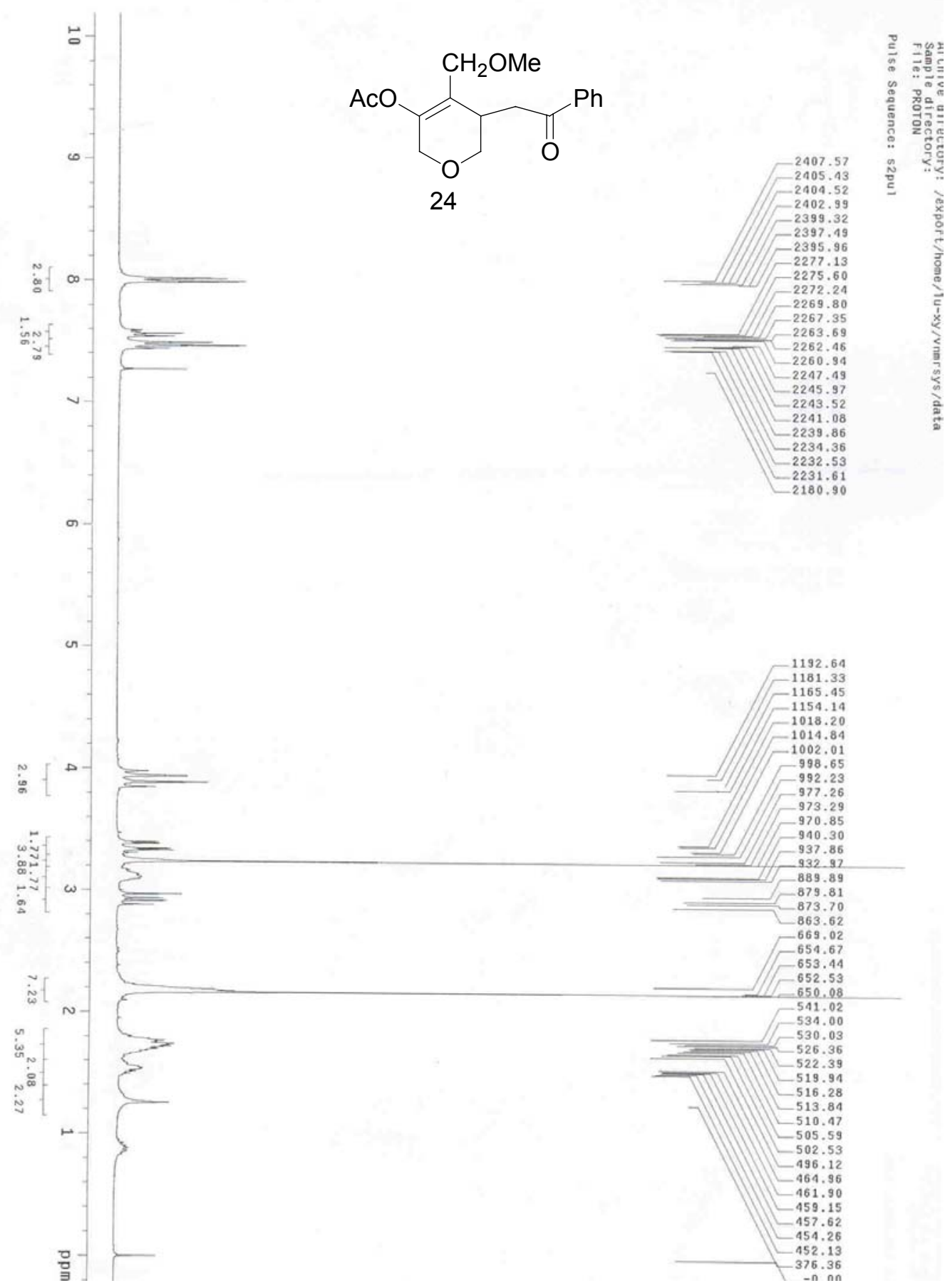



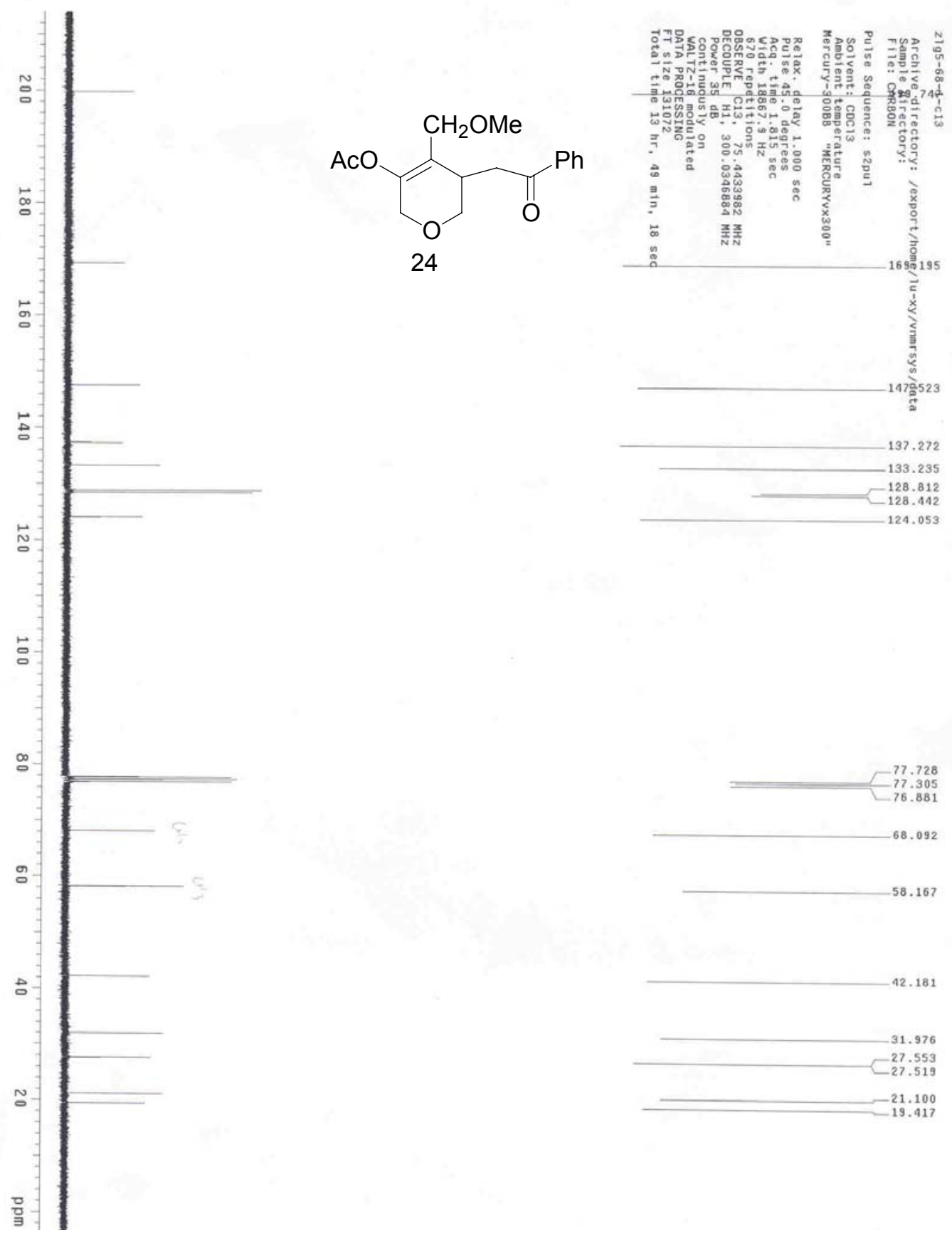


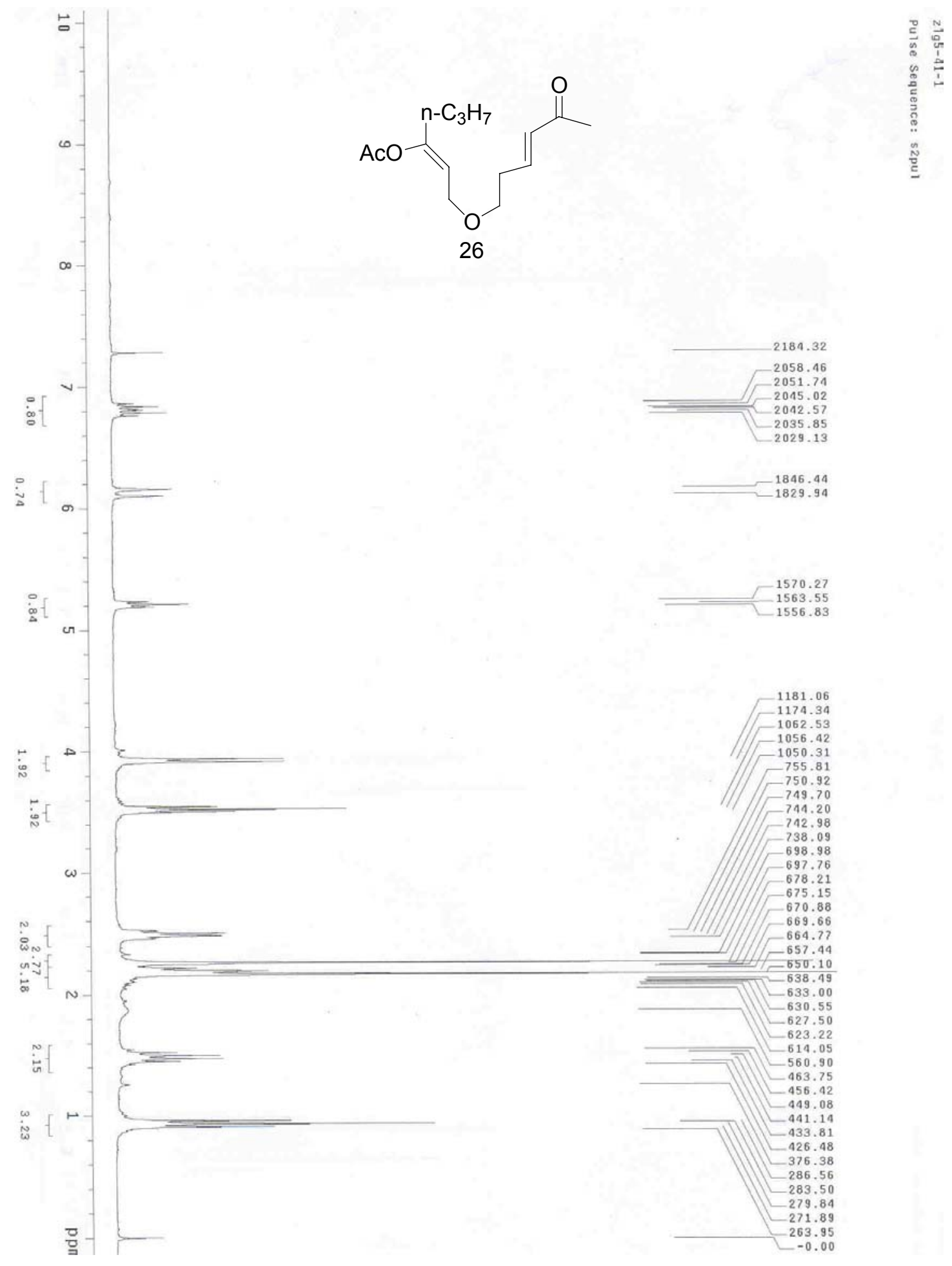




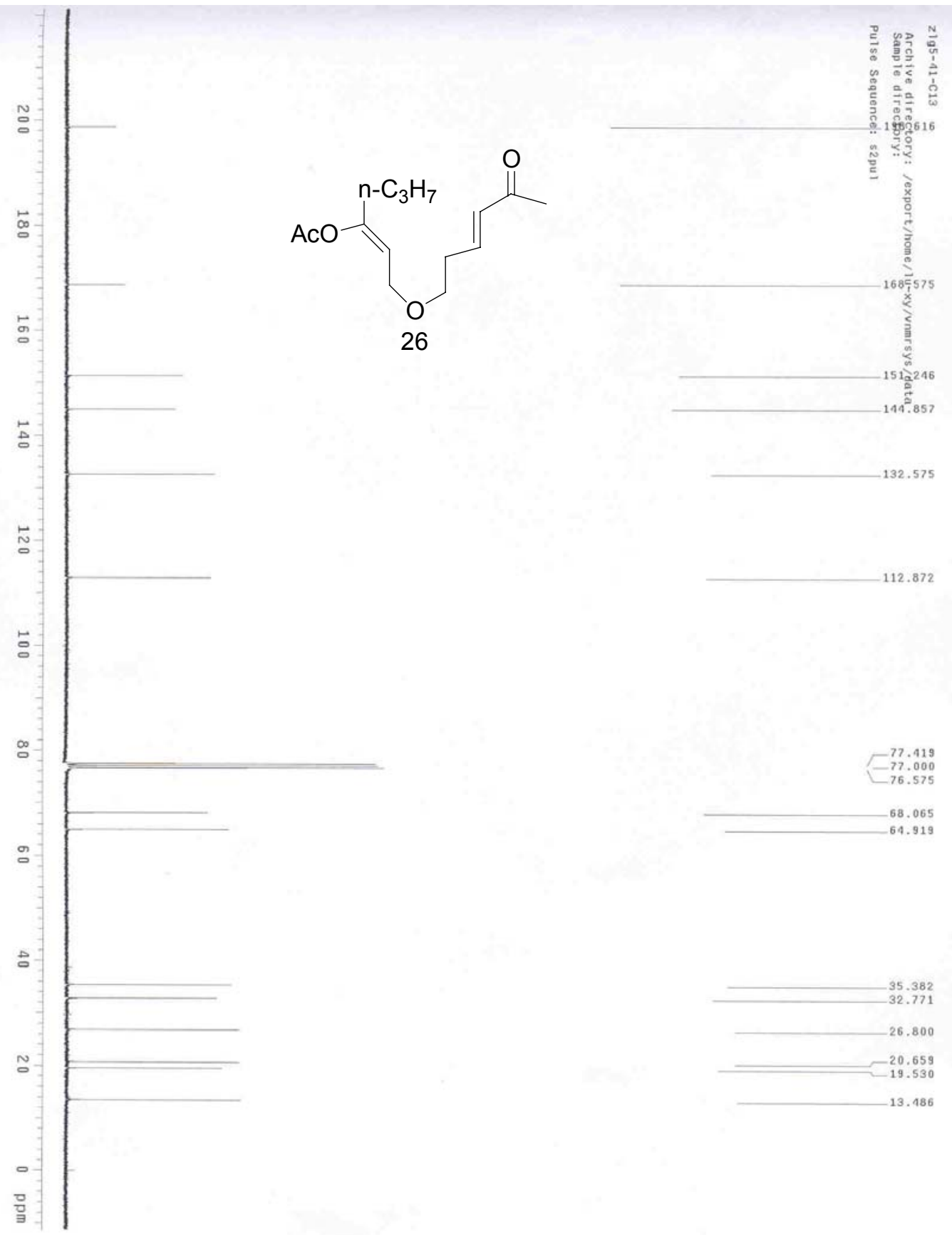

